\title{
Regressing Melanoma
}

National Cancer Institute

\section{Source}

National Cancer Institute. Regressing Melanoma. NCI Thesaurus. Code C4228.

A skin lesion characterized by the disappearance of the melanoma cells from the primary melanoma site. The disappearance of the malignant cells is associated with fibroplasia of the papillary dermis. According to some authors, complete regression of the primary melanoma may occur in $4-8 \%$ of patients. 